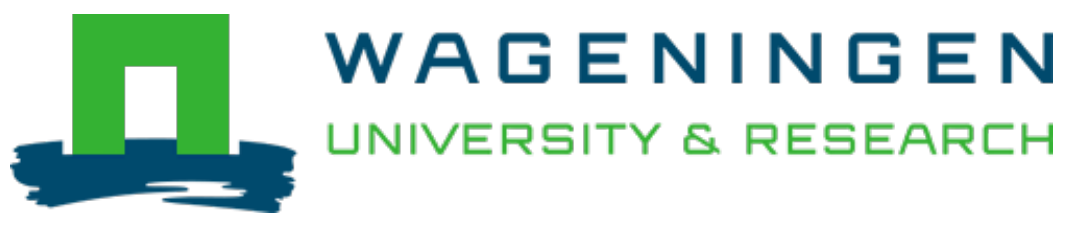

\title{
Multiple stressors in Mediterranean coastal wetland ecosystems : Influence of salinity and an insecticide on zooplankton communities under different temperature conditions
}

\author{
Chemosphere \\ Vilas-Boas, Jéssica Andrade; Arenas-Sánchez, Alba; Vighi, Marco; Romo, Susana; Brink, Paul J. et al \\ https://doi.org/10.1016/j.chemosphere.2020.129381
}

This article is made publicly available in the institutional repository of Wageningen University and Research, under the terms of article $25 \mathrm{fa}$ of the Dutch Copyright Act, also known as the Amendment Taverne. This has been done with explicit consent by the author.

Article $25 \mathrm{fa}$ states that the author of a short scientific work funded either wholly or partially by Dutch public funds is entitled to make that work publicly available for no consideration following a reasonable period of time after the work was first published, provided that clear reference is made to the source of the first publication of the work.

This publication is distributed under The Association of Universities in the Netherlands (VSNU) 'Article $25 \mathrm{fa}$ implementation' project. In this project research outputs of researchers employed by Dutch Universities that comply with the legal requirements of Article 25fa of the Dutch Copyright Act are distributed online and free of cost or other barriers in institutional repositories. Research outputs are distributed six months after their first online publication in the original published version and with proper attribution to the source of the original publication.

You are permitted to download and use the publication for personal purposes. All rights remain with the author(s) and / or copyright owner(s) of this work. Any use of the publication or parts of it other than authorised under article $25 \mathrm{fa}$ of the Dutch Copyright act is prohibited. Wageningen University \& Research and the author(s) of this publication shall not be held responsible or liable for any damages resulting from your (re)use of this publication.

For questions regarding the public availability of this article please contact openscience.library@wur.nl 


\title{
Multiple stressors in Mediterranean coastal wetland ecosystems: Influence of salinity and an insecticide on zooplankton communities under different temperature conditions
}

\author{
Jéssica Andrade Vilas-Boas ${ }^{\mathrm{a}, \mathrm{b}}$, Alba Arenas-Sánchez ${ }^{\mathrm{c}, 1}$, Marco Vighi ${ }^{\mathrm{c}}$, Susana Romo ${ }^{\mathrm{d}}$, \\ Paul J. Van den Brink ${ }^{\text {e, f }}$, Roberto Júnio Pedroso Dias ${ }^{a, b}$, Andreu Rico ${ }^{c, *}$ \\ ${ }^{a}$ Laboratório de Protozoologia, Instituto de Ciências Biológicas, Universidade Federal de Juiz de Fora 36036-900, Juiz de Fora, Minas Gerais, Brazil \\ ${ }^{\mathrm{b}}$ Programa de Pós-graduação Biodiversidade e Conservação da Natureza, Universidade Federal de Juiz de Fora 36036-900, Juiz de Fora, Minas Gerais, \\ Brazil \\ ${ }^{c}$ IMDEA Water Institute, Science and Technology Campus of the University of Alcalá, Avenida Punto Com 2, 28805, Alcalá de Henares, Madrid, Spain \\ ' Departamento de Ecología, Facultad de Biología, Universitat de València, E-46100, Burjasot, Valencia, Spain \\ e Aquatic Ecology and Water Quality Management Group, Wageningen University, P.O. Box 47, 6700 AA Wageningen, the Netherlands \\ ${ }^{\mathrm{f}}$ Wageningen Environmental Research, Wageningen University \& Research, P.O. Box 47, 6700, AA Wageningen, the Netherlands
}

\section{H I G H L I G H T S}

- Multiple stressor effects investigated on Mediterranean zooplankton communities.

- Temperature $(\mathrm{T})>$ salinity $(\mathrm{S})>$ chlorpyrifos $(\mathrm{CPF})$ affected community structure.

- Community effects of S and CPF were influenced by T regime.

- $\mathrm{S}$ and CPF resulted in antagonistic effects on sensitive taxa (Cladocera).

- There was no significant interaction between the three stressors (T, S, CPF).

\section{A R T I C L E I N F O}

\section{Article history:}

Received 16 November 2020

Received in revised form

15 December 2020

Accepted 17 December 2020

Available online 21 December 2020

Handling Editor: James Lazorchak

\section{Keywords:}

Climate change

Multiple stressors

Pesticides

Salinization

Coastal lagoons

\begin{abstract}
A B S T R A C T
Temperature increase, salinity intrusion and pesticide pollution have been suggested to be among the main stressors affecting the biodiversity of coastal wetland ecosystems. Here we assessed the single and combined effects of these stressors on zooplankton communities collected from a Mediterranean coastal lagoon. An indoor microcosm experiment was designed with temperature variation $\left(20^{\circ} \mathrm{C}\right.$ and $\left.30^{\circ} \mathrm{C}\right)$, salinity (no addition, $2.5 \mathrm{~g} / \mathrm{L} \mathrm{NaCl}$ ) and the insecticide chlorpyrifos (no addition, $1 \mu \mathrm{g} / \mathrm{L}$ ) as treatments. The impact of these stressors was evaluated on water quality variables and on the zooplankton comunity (structure, diversity, abundance and taxa responses) for 28 days. This study shows that temperature is the main driver for zooplankton community change, followed by salinity and chlorpyrifos. The three stressors contributed to a decrease on zooplankton diversity. The increase of temperature contributed to an increase of zooplankton abundance. Salinity generally affected Cladocera, which resulted in a Copepoda increase at $20^{\circ} \mathrm{C}$, and a reduction in the abundance of all major zooplankton groups at $30^{\circ} \mathrm{C}$. The insecticide chlorpyrifos affected primarily Cladocera, altough the magnitude and duration of the direct and indirect effects caused by the insecticide substantially differed between the two temperature scenarios. Chlorpyrifos and salinity resulted in antagonistic effects on sensitive taxa (Cladocera) at $20^{\circ} \mathrm{C}$ and $30^{\circ} \mathrm{C}$. This study shows that temperature can influence the direct and indirect effects of salinity and pesticides on zooplankton communities in Mediterranean coastal wetlands, and highlights vulnerable taxa and ecological responses that are expected to dominate under future global change scenarios.
\end{abstract}

(C) 2020 Elsevier Ltd. All rights reserved.

\footnotetext{
* Corresponding author.

E-mail address: andreu.rico@imdea.org (A. Rico).

1 These authors contributed equally to this study.
}

\section{Introduction}

Coastal wetland ecosystems support a large share of the global 
aquatic biodiversity and provide important ecological services, such as nutrient cycling, food provision or erosion control (Pérez-Ruzafa et al., 2010; Barbier, 2011). Several authors have identified wetland ecosystems in the Mediterranean region as particularly vulnerable to climate change and anthropogenic pressures (Romo et al., 2005; 2016; Pérez-Ruzafa et al., 2011; Osland et al., 2016; Gabler et al., 2017). Low precipitation and increasing evaporation associated to climate change, and the increasing subtraction of freshwater resources for agricultural irrigation and urban expansion modify significantly their water balance (Navarro-Ortega et al., 2012). The reduction of freshwater inputs generally results in an increase of salinity, mainly due to seawater intrusion (Millán et al., 2011; Cañedo-Argüelles et al., 2016, 2019), which modifies physicochemical ecosystem variables and changes the metabolism of aquatic organisms, interfering with their life-history traits and fitness (Rokneddine and Chentoufi, 2004; Jeppesen et al., 2015). For instance, Nielsen et al. (2003) described decreased diapausing eggs' emergence of zooplankton and richness related to slight increases in water salinity. According to Coldsnow et al. (2017), increasing salinity generally results in a decrease of cladocerans and copepods, and an increase of rotifers, which facilitates the increase of phytoplankton blooms and the alteration of functional ecosystem parameters. Furthermore, salinity can induce changes in species competition patterns and alter predation regimes, which affect population dynamics and the structure of freshwater communities (Hintz et al., 2018; Bracewell et al., 2019).

Chemical emissions from agricultural, industrial and urban activities are also important drivers of biodiversity loss in coastal wetlands (Liu and Diamond, 2005; Navarro-Ortega et al., 2012; Bassi et al., 2014). Pesticides, which are commonly used in rice, vegetable and fruit production surrounding coastal wetlands, have been identified as one of the chemical groups of highest environmental concern (Picó et al., 2019). Particularly, organophosphorus insecticides, and some carbamate and azole fungicides, have been identified as a potential threat to freshwater biodiversity in Mediterranean river estuaries and wetlands (Ccanccapa-Cartagena et al., 2019). Aquatic ecosystems in Mediterranean regions are naturally influenced by seasonal temperature variations, reaching water temperatures of nearly $30^{\circ} \mathrm{C}$ during the summer period. According to the 5th report from the Intergovernmental Panel for Climate Change (IPCC, 2014), the prevalence of summer peak temperatures, heatwaves, and periods dominated by high water temperature is expected to increase markedly in the Mediterranean region in the coming years. Increasing temperatures may influence the metabolic rate of aquatic organisms, leading to different reproductive patterns and species interactions, which affect the structure of communities (Gillody et al., 2001; Devreker et al., 2009) and their vulnerability to additional stressors (Klausmeyer and Shaw, 2009; Mantyka-Pringle et al., 2012; Rojo et al., 2017; Arenas-Sánchez et al., 2019).

Despite the elevated number of studies describing the influence of temperature, salinity and chemical pollution in freshwater ecosystems, evidence on the interactive effects of these stressors remains limited (Mantyka-Pringle et al., 2014; Jackson, 2018; Arenas-Sánchez et al., 2019). Heugens et al. (2001) and Bracewell et al. (2019) published literature reviews discussing the influence of temperature, nutritional state and salinity on the sensitivity of different groups of aquatic organisms to various classes of chemicals. Moreover, previous review papers have considered the interaction between contaminants and temperature (Cairns et al., 1975), contaminants and salinity (Hall and Anderson, 1995) and the combination of these three factors (McLusky et al., 1986). These studies show that temperature generally tends to increase metabolic rates, leading to an increase in water exchange that results in a higher uptake and toxicity of chemicals to some aquatic organisms. No clear trend was observed for the combined effects of organic chemicals and salinity, except for organophosphate insecticides, for which a synergistic effect has been described (Heugens et al., 2001). This finding was based on laboratory experiments performed with mosquito larvae (Aedes taeniorhynchus) and brine shrimps (Artemia sp.) exposed to aldicarb and dimethoate under isosmotic and hyperosmotic conditions (Song and Brown, 1998). Particularly, for mosquito larvae, the short term $\mathrm{LC}_{50}$ for dimethoate was an order of magnitude lower under hyperosmotic conditions, suggesting that further studies are needed to assess the interactive effects of organophosphate insecticides and salinity in freshwater organisms.

The aim of the present study was to assess the effects of salinity, insecticide pollution and temperature regimes on zooplankton communities characteristic of a Mediterranean coastal wetland ecosystem. The main hypotheses were that different temperatures will influence community structure, and affect the single and combined effects of both chemical stressors. Also, as previously described, we expected that an increase in salinity enhances the uptake and sensitivity of some freshwater taxa to insecticide pollution. In our study, these hypotheses were tested by performing an indoor microcosm experiment with planktonic organisms collected from the Albufera lagoon (Valencia, Spain). The Albufera lagoon is a shallow (mean depth $1.2 \mathrm{~m}$ ), oligohaline (salinity $1-2 \%$ ), polymictic and eutrophic-to-hypereutrophic lagoon surrounded by intensive agriculture and urbanization (Romo et al., 2005). In our study, zooplankton was selected as focal taxonomic group due to their high sensitivity and rapid response to the selected stressors, and due to their relevant contribution as a food resource for fish, amphibians and birds in aquatic ecosystems. As test compound, we selected the organophosphate insecticide chlorpyrifos (CPF) [O, O-diethyl o-(3, 5, 6-trichloro-2-pyridyl) phosphorothioate]. CPF is a broad-spectrum insecticide that is widely used throughout the world in several agricultural crops (Cortina-Puig et al., 2010). This compound has been detected in a wide range of coastal wetland ecosystems and has been identified as highly toxic to aquatic non-target invertebrates and fish in the Mediterranean as well as in other regions (Moreno-González and León, 2017; Huang et al., 2020; Rico et al., 2020). Since January 2020, CPF has been banned in the European Union due to its possible genotoxic and neurological effects in children (EC 2020). However, it is considered a very good model compound given the amount of published data regarding its environmental exposure and effects (Huang et al., 2020). Moreover, it is expected to be replaced by surrogate pesticides with the same toxicological mode of action in European agriculture. The salinity and thermal regimes included in this study were based on monitoring data from the regional agricultural ministry (Valencian Agricultural Ministry, 2019) and represent realistic worst-case scenarios for the coastal aquatic system from which the zooplankton was collected. Overall, this study contributes to improve our understanding on the resilience of zooplankton communities to multiple stressors in Mediterranean coastal wetlands, and to identify vulnerable taxa and ecological responses that are expected to dominate under future global change scenarios.

\section{Materials and methods}

\subsection{Experimental design}

Thirty two microcosms (diameter $20.5 \mathrm{~cm}$, total height $37 \mathrm{~cm}$ ) were set-up in the ecotoxicology laboratory of the IMDEA Water Institute. The microcosms were filled with $12 \mathrm{~L}$ of water and plankton collected from the Albufera lagoon $\left(39^{\circ} 20 \mathrm{~N}, 0^{\circ} 21 \mathrm{~W}\right)$. Water was collected on the 1 st of October of 2019 from the inner 
part of the lagoon and transported to the laboratory. Zooplankton was collected on the same date and concentrated in-situ with a plankton net (mesh size: $55 \mu \mathrm{m}$ ). Afterwards, it was distributed homogeneously over the test microcosms.

The experiment followed a factorial design with three treatments and two different levels each, and was run with four replicates $(\mathrm{n}=4)$. The treatments were: temperature $\left(20^{\circ} \mathrm{C}\right.$ and $\left.30^{\circ} \mathrm{C}\right)$, salinity (no salt addition, $2.5 \mathrm{~g} / \mathrm{L}$ salt addition in form of $\mathrm{NaCl}$ ) and $\mathrm{CPF}$ exposure (i.e., control, $1 \mu \mathrm{g} / \mathrm{L}$ ). The temperature of the $30^{\circ} \mathrm{C}$ microcosms was increased slowly during the first 7 days using a temperature-controlled water bath. The salinity $(\mathrm{NaCl})$ was added at a rate of $0.5 \mathrm{~g} / \mathrm{L}$ per day during 5 days (until reaching $2.5 \mathrm{~g} / \mathrm{L}$ ) using a saline stock solution of $100 \mathrm{~g} / \mathrm{L}$ and adding $60 \mathrm{~mL}$ per day to each exposed microcosm. CPF was added as a single dose 14 days after the set-up of the experiment. The choice of the temperature and salinity were done according to available monitoring data from the Albufera lagoon (see Supporting Information, Figures S1 and S2), and represent maximum temperature and salinity values of late summer periods.

The microcosms were subjected to a light/dark regime of 16:8 h. The light intensity was 3112 lux, which was considered powerful enough to maintain the phytoplankton community in the microcosms according to the OECD protocol for toxicity testing with algae (OECD 2006). Aeration was set inside of each microcosm with a low air flow to prevent extreme anoxic conditions, and to simulate mild water movement from air characteristic of natural ecosystems. The whole experiment had a duration of 6 weeks, with an aclimatization/adaptation period of 2 weeks and a post-insecticide exposure period of 4 weeks. The microcosms were checked weekly and refilled with demineralised water when excessive evaporation occurred.

\subsection{Chlorpyrifos dosing, sampling, and analysis}

A concentrated CPF stock solution of $12 \mathrm{mg} / \mathrm{L}$ in methanol was prepared. Aliquots $(1 \mathrm{~mL})$ of this stock solution were evenly distributed over the water surface of the corresponding microcosms and stirred with a glass pipette to reach a CPF concentration of $1 \mu \mathrm{g} / \mathrm{L}$. Methanol ( $1 \mathrm{~mL}$ ) was added to each chemical control according to the requirements specified by the OECD (2000) guidelines. Nominal concentrations were calculated on the basis of concentrations in the stock solution.

Water samples $(100 \mathrm{~mL})$ were taken from the microcosms by means of a glass pipette and transferred into glass flasks to measure CPF concentrations. Water samples were collected $2 \mathrm{~h}$, and 1, 3, 7 and 10 days after the application in the microcosms that received the CPF application. Samples in the microcoms that did not receive CPF were also collected on days 1 and 10 relative to the CPF application in order to assess any potential cross contamination. In general, samples were analyzed within $48 \mathrm{~h}$ after collection. When this was not possible, they were frozen and stored at $-20^{\circ} \mathrm{C}$ until further analysis.

CPF concentrations in the microcosm water were analyzed using a gas chromatograph (GC) system (Agilent $7890 \mathrm{~A}$ ) coupled to a mass spectrometer (MS) with a triple quadrupole analyzer (Agilent 7000 GC/MS Triple Quad). The GC column used was a HP-5ms (Agilent) capillary column. Chlorpyrifos was extracted using the Stir Bar Sorptive Extraction (or Twister) technique. The Twister was placed in an Erlenmeyer flask with $100 \mathrm{~mL}$ of water sample containing the internal standard (chlorpyrifos-d $10,20 \mu \mathrm{L}$ of a standard solution of $250 \mathrm{ng} / \mathrm{mL}$ ) and stirred at $850 \mathrm{rpm}$ overnight. After extraction, the stir bar was introduced in a glass thermal desorption tube, placed in the thermal desorption unit of the GC-MS. The limit of quantification (LOQ) and the limit of detection (LOD) of the method were $30 \mathrm{ng} / \mathrm{L}$ and $3 \mathrm{ng} / \mathrm{L}$, respectively. The mean recovery of the method was: $98 \%$ (Relative Standard Deviation, RSD: $2 \%$ ) at $30 \mathrm{ng} / \mathrm{L}$, and $105 \%$ (RSD: $5 \%$ ) at $100 \mathrm{ng} / \mathrm{L}(\mathrm{n}=3)$.

\subsection{Water quality measurements}

Water quality variables (i.e., temperature, electric conductivity, $\mathrm{pH}$, dissolved oxygen and total dissolved solids) were measured with a multi-meter probe (model HI98194; HANNA Instruments) at $10 \mathrm{~cm}$ depth on days $-14,-7,-4,7,14$ and 28 relative to the CPF application. Water samples ( $1 \mathrm{~L}$ ) were collected on days -3 and 14 relative to the CPF application for assessing ammonia, nitrate, orthophosphate and total P (TP) concentrations. Nitrate and ammonia concentrations were used to calculate the dissolved inorganic nitrogen (DIN). Chlorophyll-a concentrations were measured on days $-3,7,14$ and 28 relative to the CPF application. Nutrient and chlorphyll-a samples were analyzed following the methods described in APHA (2005). The results of the water chlorophyll- $a$ and nutrient concentrations were used to characterize the systems and to evaluate the possible influence of the tested stressors on ecosystem functional parameters.

\subsection{Zooplankton sampling and determination}

Zooplankton samples were taken on days $-4,7,14$ and 28 relative to the CPF application. The samples $(1.5 \mathrm{~L})$ were collected using a suction pump and filtered through a zooplankton net (mesh size: $55 \mu \mathrm{m}$ ). Subsequently, the filtered water was returned to the original microcosm. The concentrated zooplankton samples (maximum volume $100 \mathrm{~mL}$ ) were preserved with Lugol's iodine solution (approximately $4 \% \mathrm{v} / \mathrm{v}$ ) and let to sediment for $24 \mathrm{~h}$. Afterwards, the supernatant was carefully removed to obtain a concentrated sample. Macrozooplankton (Cladocera, Copepoda, Ostracoda) were identified and counted in the entire zooplankton sample using an Olympus SZx2-TR30 stereomicroscope (magnification 20×). Microzooplankton (Rotifera) and Copepoda nauplii were assessed in $1 \mathrm{~mL}$ sub-samples, which were analyzed with a binocular Olympus UCTR30-2 microscope (magnification 100×). Macrozooplankton and microzooplankton taxa were identified to the lowest practical taxonomic resolution level. Abundance of each taxon was re-calculated to number of individuals per litre of the microcosm water.

\subsection{Data analyses}

The half-life of CPF (DT50) in the different temperature and salinity treatments was calculated by dividing $\operatorname{Ln}(2)$ by the dissipation coefficient. The dissipation coefficients were calculated by means of linear regression of the ln-transformed measured concentrations with the software Microsoft Excel version 2010 assuming first-order kinetics.

The influence of temperature, salinity and CPF on the zooplankton community was first evaluated with a Permutation Multivariate Analysis of Variance (PERMANOVA) test based on Euclidean distances with 999 Monte Carlo permutations (for further details see Anderson, 2001). A Principal Response Curve (PRC) analysis was performed in order to evaluate the responses associated to the different temperature scenarios, the responses associated to salinity and CPF separately in each temperature scenario, and the interaction between salinity and CPF in each of the two temperature scenarios. In each PRC analysis, the overall significance of the treatments on the dataset was tested by 999 Monte Carlo permutations under the Redundancy Analysis (RDA) option (for further details see Van den Brink and Ter Braak, 1999). The first four PRCs were inspected since the different stressors may result in different effects on the evaluated datasets, so it was expected that 
more than one PRC is needed to display the different community responses. In addition, a variation partitioning analysis was performed to assess the relative influence of each stressor on the zooplankton community using the RDA option (for rationale, see Peres-Neto et al., 2006). The PERMANOVA analyses were performed using the SIMPER version 7 Software (Clarke and Gorley, 2015). The PRC and the variation partitioning analyses were performed using the CANOCO Software, version 5 (Ter Braak and Šmilauer, 2012). In all cases data were $\log (x+1)$ transformed prior to the statistical analyses, and a significance level of 0.05 was used to distinguish significant responses associated to each treatment and their interaction.

Population-level analyses were performed only with selected taxa: Diaphanosoma sp., Moina sp., Anuraeopsis sp. and Lecane lunari. These taxa were selected based on their relative large positive or negative response to the evaluated stressors as result of the PRC analysis (i.e., high or low $b_{k}$ values). Population-level responses were evaluated by performing a three-way ANOVA for each sampling date, and including temperature, salinity and CPF as independent variables. Prior to the analysis, abundance data were log $(x+1)$, exponential, $\log 10$, and square root transformed, and the best transformation was chosen for each sampling date based on the results of the Levene's variance homogeneity test and the Shapiro-Wilk normality test. When one of the two assumptions were not met, homogeneity of variances was prevailing over normality. The same analysis was performed for the calculated diversity (Simpson's index, Simpson 1949) and total zooplankton abundance, as well as for the total abundance of Cladocera, Copepoda and Rotifera, and for the water quality parameters (including chlorophyll-a). In this case, a first assessment of homogeneity of variances and normality was performed with non-transformed data, and only when data was not complying with the assumptions, transformed data was used based on the same criteria as described above for the population-level analyses. Ostracoda were not further evaluated since their abundances were extremely low during the course of the experiment in all treatments. The three-way ANOVAs and the variance homogeneity and normality tests were performed with the Software Jamovi 1.2.2.0 (Şahin and Aybek, 2019). The significant influence of the single stressors or their interactions on the response variables were established when the calculated p-value was lower than 0.05 , although marginally significant values $(0.05<\mathrm{p}$-value $<0.1)$ are also indicated in the text.

\section{Results}

\subsection{Chlorpyrifos concentrations}

CPF dosing was properly done based on the concentrations measured in the stock solution. After application, CPF dissipated relatively fast from the water column. The calculated DT50 at $20^{\circ} \mathrm{C}$ was $3.10 \mathrm{~d}$ in the microcosms that did not receive salt addition, and $4.40 \mathrm{~d}$ in the microcosms that received salt addition. At $30^{\circ} \mathrm{C}$, the DT50s were 1.61 and $1.85 \mathrm{~d}$ in the microcosms without salt and with salt addition, respectively. Therefore, the dissipation of CPF at $30^{\circ} \mathrm{C}$ was generally twice more rapid than at $20^{\circ} \mathrm{C}$, and salinization resulted in a slight delay on the dissipation of CPF.

\subsection{Water quality parameters}

The mean and standard deviation of the water quality variables measured in the microcosms are shown in Table 1 . The measured temperatures in the $20^{\circ} \mathrm{C}$ treatment were slightly above $20^{\circ} \mathrm{C}$, but in the $30^{\circ} \mathrm{C}$ treatment they were very close to the intended temperature. Electric conductivity was more than two times higher in the microcosms that received salt addition, which is consistent with the expected salinity increase (Table 1).

The three-way ANOVA indicates that all water quality variables were affected by temperature conditions (Table S1). Water $\mathrm{pH}$ ranged between 7.7 and 9.4. It was found to be significantly lower in the $30^{\circ} \mathrm{C}$ treatment, and decreased after the salt and CPF addition (Table S1). As expected, dissolved oxygen concentrations were significantly higher in the $20^{\circ} \mathrm{C}$ microcosms $(7.7-8.1 \mathrm{mg} / \mathrm{L})$ than in the $30^{\circ} \mathrm{C}$ ones $(5.6-5.9 \mathrm{mg} / \mathrm{L})$. Oxygen levels significantly increased after the CPF addition, and in the treatments affected by CPF and salinity. TDS values were generally higher in the microcosms that had higher temperatures and received salt addition. Ammonia concentrations significantly increased in the $30^{\circ} \mathrm{C}$ microcosms, and in the ones exposed to CPF and salinity (Table S1), up to $1.7 \mathrm{mg} / \mathrm{L}$ in the $30^{\circ} \mathrm{C}$ microcosms that received salt on day -4 . The interaction between temperature and salinity, and temperature and CPF also resulted in significantly higher values on day 14 (Table S1). DIN levels were generally similar across the different treatments, with slightly higher values in the $30^{\circ} \mathrm{C}$ treatment and in the salinity ones. Conversely, TP was significantly lower in the treatment at $30^{\circ} \mathrm{C}$, with no consistent differences in the microcosms that received salinity or $\mathrm{CPF}$. Mean chlorophyll- $a$ concentrations ranged between 58 and $125 \mu \mathrm{g} / \mathrm{L}$, which are representative of eutrophic freshwater ecosystems (Table 1). Chlorophyll-a concentrations were significantly lower in the microcosms at $30^{\circ} \mathrm{C}$ (Table S1) and were notably reduced by the addition of salt in both temperature scenarios (Table 1).

\subsection{Zooplankton responses}

Eigtheen zooplankton taxa were identified, most of them belonging to the Rotifera phylum (12 taxa) followed by the Cladocera order (3 taxa: Diaphanosoma sp., Alona sp., Moina sp.). Copepoda were subdivided into Copepoda nauplii and Cyclopoida (including adults and copepodites), and Ostracoda were not further identified.

The variation partitioning analysis perfomed to asses the relative influence of each stressor on the zooplankton community showed that temperature was the main stressor accounting for the zooplankton community variation (45\% of explained variation), followed by salinity (32\%) and CPF (24\%; Table S2). The PERMANOVA analysis indicated that the different temperature regime significantly influenced the zooplankton community during the whole experimental period (Table 2). At $30^{\circ} \mathrm{C}$, the zooplankton diversity was signficantly reduced, while the total abundance was higher, particularly at the beginning of the experiment (Table 3; Fig. 1). The three-way ANOVA indicated a significant, or marginally significant, increase of Cladocera, Copepoda and Rotifera at $30^{\circ} \mathrm{C}$ for the majority of sampling dates (Table 3; Fig. 1). The PRC analysis performed with the temperature controls shows that temperature had a significant influence on the community structure (Table 4). The taxa that showed a marked increase in abundance at $30^{\circ} \mathrm{C}$ were Brachionus falcatus, Diaphanosoma sp. and Copepoda nauplii, while Ascomorpha sp. and Moina sp. showed a slight decrease as compared to the $20^{\circ} \mathrm{C}$ treatment (Figs. 2 and 3).

The PERMANOVA analysis showed that salinity significantly influenced the zooplankton community from day 7 relative to the CPF application until the end of the experiment (Table 2). The salinity treatment significantly reduced the zooplankton diversity and Cladocera abundance (Table 3, Fig. 1). The interaction between temperature and salinity was significant during day -4 to day 14 , indicating that the community effects of salinity were different at the different temperature regimes (Table 2). The temperature-salinity interaction was significant for total zooplankton abundance at the beginning of the experimental period (day -4 and 7), and for Cladocera (day 7 and 14), Copepoda 
Table 1

Water quality parameters (mean \pm standard deviation) measured in the different treatments during the experiment. The raw data are provided in Appendix I.

\begin{tabular}{|c|c|c|c|c|c|c|c|c|}
\hline Parameters & T20 & $\mathrm{T} 20-\mathrm{S}$ & T20-CPF & $\mathrm{T} 20-\mathrm{S}-\mathrm{CPF}$ & T30 & T30-S & T30-CPF & T30-S-CPF \\
\hline Temperature $\left({ }^{\circ} \mathrm{C}\right)$ & $21.5 \pm 0.3$ & $21.5 \pm 0.3$ & $21.5 \pm 0.3$ & $21.9 \pm 1.7$ & $29.9 \pm 1.5$ & $29.4 \pm 1.4$ & $29.8 \pm 1.5$ & $29.5 \pm 1.4$ \\
\hline $\mathrm{EC}(\mu \mathrm{S} / \mathrm{cm})$ & $1918 \pm 206$ & $5540 \pm 1722$ & $2053 \pm 454$ & $5315 \pm 2097$ & $2021 \pm 222$ & $5787 \pm 1793$ & $1943 \pm 462$ & $5720 \pm 1768$ \\
\hline $\mathrm{pH}$ & $8.2 \pm 0.21$ & $8.3 \pm 0.23$ & $8.3 \pm 0.11$ & $8.3 \pm 0.19$ & $8.2 \pm 0.22$ & $8.1 \pm 0.15$ & $8.1 \pm 0.33$ & $8.1 \pm 0.21$ \\
\hline DO (\%) & $94.3 \pm 19.1$ & $103 \pm 11.7$ & $137 \pm 187$ & $133 \pm 183.8$ & $85.7 \pm 8.9$ & $87.0 \pm 7.3$ & $83.0 \pm 9.3$ & $87.0 \pm 8.6$ \\
\hline $\mathrm{DO}(\mathrm{mg} / \mathrm{L})$ & $7.8 \pm 0.9$ & $8.1 \pm 0.8$ & $8.1 \pm 0.6$ & $7.7 \pm 1.3$ & $5.9 \pm 0.7$ & $5.9 \pm 0.5$ & $5.6 \pm 0.7$ & $5.9 \pm 0.6$ \\
\hline TDS (mg/L) & $964 \pm 117$ & $2770 \pm 861$ & $1053 \pm 203$ & $2658 \pm 919$ & $1014 \pm 110$ & $2713 \pm 1018$ & $1008 \pm 356$ & $2848 \pm 883$ \\
\hline Ammonia (mg/L) & $0.01 \pm 0.02$ & $<0.01$ & $0.01 \pm 0.01$ & $0.20 \pm 0.3$ & $0.19 \pm 0.2$ & $0.3 \pm 0.4$ & $0.39 \pm 0.35$ & $0.38 \pm 0.33$ \\
\hline $\mathrm{N}-\mathrm{NO} 3(\mathrm{mg}-/ \mathrm{L})$ & $1.23 \pm 0.21$ & $1.29 \pm 0.13$ & $1.22 \pm 0.17$ & $1.19 \pm 0.16$ & $1.13 \pm 0.10$ & $1.72 \pm 0.53$ & $1.28 \pm 0.25$ & $1.82 \pm 0.57$ \\
\hline $\mathrm{DIN}(\mu \mathrm{g} / \mathrm{L})$ & $0.29 \pm 0.06$ & $0.29 \pm 0.03$ & $0.28 \pm 0.05$ & $0.37 \pm 0.26$ & $0.35 \pm 0.19$ & $0.72 \pm 0.46$ & $0.67 \pm 0.33$ & $0.65 \pm 0.34$ \\
\hline Ortophosphate (mg/L) & $19.8 \pm 9.4$ & $22.9 \pm 7.4$ & $23.7 \pm 8.85$ & $15.4 \pm 21.2$ & $11.7 \pm 6.4$ & $6.7 \pm 4.6$ & $7.4 \pm 4.1$ & $9.5 \pm 3.7$ \\
\hline $\mathrm{TP}(\mathrm{mg} / \mathrm{L})$ & $96.7 \pm 31.9$ & $94.9 \pm 16.4$ & $99.4 \pm 17.2$ & $67.6 \pm 21.3$ & $50.6 \pm 11.9$ & $52.2 \pm 24.5$ & $42.2 \pm 14.9$ & $59.7 \pm 15.7$ \\
\hline Chlorophyll-a $(\mu \mathrm{g} / \mathrm{l})$ & $125 \pm 167$ & $81.9 \pm 110$ & $103 \pm 138$ & $69.1 \pm 90.3$ & $110 \pm 146$ & $70.3 \pm 90.3$ & $86.9 \pm 116.1$ & $57.7 \pm 59.2$ \\
\hline
\end{tabular}

EC: electric conductivity; DO: dissolved oxygen; TDS: total dissolved solids; T20: temperature at $20^{\circ} \mathrm{C}$; $\mathrm{T} 30$ : temperature at $30{ }^{\circ} \mathrm{C}$.

Table 2

Results of the PERMANOVA analysis performed with the zooplankton dataset. Bold values indicate significant effects ( $\mathrm{p}$-value $<0.05$ ) of the single stressors or their interactions. T: temperature, CPF: chlorpyrifos, S: salinity, D: days relative to the chlorpyrifos application.

\begin{tabular}{llllllll}
\hline Day & $\mathrm{T}$ & $\mathrm{S}$ & $\mathrm{CPF}$ & $\mathrm{TxS}$ & $\mathrm{TxCPF}$ & $\mathrm{SxCPF}$ & $\mathrm{TxSxCPF}$ \\
\hline D-4 & $<\mathbf{0 . 0 0 1}$ & 0.152 & 0.181 & $\mathbf{0 . 0 0 2}$ & 0.066 & 0.512 & 0.182 \\
D7 & $<\mathbf{0 . 0 0 1}$ & $<\mathbf{0 . 0 0 1}$ & $<\mathbf{0 . 0 0 1}$ & $\mathbf{0 . 0 0 5}$ & $\mathbf{0 . 0 0 8}$ & 0.365 & 0.639 \\
D14 & $<\mathbf{0 . 0 0 1}$ & $<\mathbf{0 . 0 0 1}$ & $<\mathbf{0 . 0 0 1}$ & $\mathbf{0 . 0 0 3}$ & 0.303 & 0.296 & 0.710 \\
D28 & $<\mathbf{0 . 0 0 1}$ & $<\mathbf{0 . 0 0 1}$ & $\mathbf{0 . 0 0 5}$ & 0.121 & $\mathbf{0 . 0 0 2}$ & $\mathbf{0 . 0 4}$ & 0.118 \\
\hline
\end{tabular}

Table 3

Results of the three-way ANOVA (p-value) performed with the diversity index (Simpson), total abundance, and Cladocera, Copepoda and Rotifera abundances. Bold values indicate significant effects ( $\mathrm{p}$-value $<0.05$ ). T: temperature, CPF: chlorpyrifos, $\mathrm{S}$ : salinity, D: days relative to the chlorpyrifos application.

\begin{tabular}{|c|c|c|c|c|c|c|c|}
\hline & $\mathrm{T}$ & $\mathrm{S}$ & $\mathrm{CPF}$ & TxS & TxCPF & SxCPF & TxSxCPF \\
\hline \multicolumn{8}{|c|}{ Diversity } \\
\hline $\mathrm{D}-4$ & $<0.001$ & 0.584 & 0.212 & 0.080 & 0.622 & 0.023 & 0.230 \\
\hline D7 & 0.008 & 0.024 & 0.073 & 0.761 & 0.891 & 0.651 & 0.237 \\
\hline D14 & $<0.001$ & 0.004 & 0.008 & 0.450 & 0.599 & 0.077 & 0.511 \\
\hline D28 & 0.066 & 0.823 & 0.304 & 0.253 & 0.036 & 0.104 & 0.142 \\
\hline \multicolumn{8}{|c|}{ Total abundance } \\
\hline$D-4$ & $<0.001$ & 0.565 & 0.766 & 0.022 & 0.023 & 0.866 & 0.448 \\
\hline D7 & 0.642 & 0.454 & 0.011 & 0.022 & 0.005 & 0.375 & 0.652 \\
\hline D14 & 0.059 & 0.899 & 0.183 & 0.294 & 0.266 & 0.681 & 0.842 \\
\hline D28 & 0.625 & 0.146 & 0.052 & 0.838 & 0.763 & 0.026 & 0.118 \\
\hline \multicolumn{8}{|c|}{ Cladocera } \\
\hline $\mathrm{D}-4$ & 0.003 & 0.216 & 0.283 & 0.095 & 0.001 & 0.800 & 0.724 \\
\hline D7 & 0.009 & 0.002 & 0.006 & 0.014 & 0.578 & 0.012 & 0.056 \\
\hline D14 & 0.438 & 0.050 & 0.003 & 0.045 & 0.152 & 0.445 & 0.934 \\
\hline D28 & 0.068 & 0.486 & 0.117 & 0.451 & 0.154 & 0.787 & 0.937 \\
\hline \multicolumn{8}{|c|}{ Copepoda } \\
\hline$D-4$ & $<0.001$ & 0.611 & 0.895 & 0.028 & 0.042 & 0.767 & 0.723 \\
\hline D7 & 0.037 & 0.532 & 0.240 & 0.360 & 0.001 & 0.901 & 0.286 \\
\hline D14 & 0.059 & 0.899 & 0.183 & 0.294 & 0.266 & 0.681 & 0.842 \\
\hline D28 & 0.081 & 0.213 & 0.955 & 0.673 & 0.250 & 0.106 & 0.269 \\
\hline \multicolumn{8}{|c|}{ Rotifera } \\
\hline$D-4$ & 0.038 & 0.449 & 0.471 & 0.105 & 0.139 & 0.048 & 0.006 \\
\hline D7 & 0.068 & 0.669 & $<0.001$ & 0.005 & 0.713 & 0.905 & 0.676 \\
\hline D14 & 0.080 & 0.052 & 0.540 & 0.357 & 0.134 & 0.617 & 0.919 \\
\hline D28 & 0.008 & 0.462 & 0.002 & 0.431 & 0.020 & 0.901 & 0.126 \\
\hline
\end{tabular}

(day -4) and Rotifera (day -7; Table 3 ). At $20^{\circ} \mathrm{C}$, salinity resulted in a decrease on Cladocera and Rotifera and an increase of Copepoda, which resulted in an increase of total abundance. At $30^{\circ} \mathrm{C}$, salinity resulted in a decrease of Cladocera, Rotifera and Copepoda, which contributed to a significant abundance decline (Fig. 1). The PRC analysis showed that, at $20^{\circ} \mathrm{C}$, salinity explained $21 \%$ of the variation (only the first PRC is significant), while at $30^{\circ} \mathrm{C}$ it explained $34 \%$ (with the first and second PRCs being significant), suggesting that the impacts of salinity on zooplankton community changes at $30^{\circ} \mathrm{C}$ were slightly larger than at $20^{\circ} \mathrm{C}$ (Table 4). This is also observed in Fig. 4, which shows that salinity effects persisted during the whole experimental period, but started earlier (some days before the CPF application) and were larger (particularly on days -4 and 7) at $30^{\circ} \mathrm{C}$ than at $20^{\circ} \mathrm{C}$. At $20^{\circ} \mathrm{C}$, the PRC shows that $\mathrm{Anu}$ raeopsis sp. and Moina sp. decreased due to salt addition, while there was an increase of Brachionis quadridentatus and Copepoda nauplii. At $30^{\circ} \mathrm{C}$, the first PRC indicates a higher treatment-related decrease of Anuraeopsis sp. (Fig. 3) and Brachionus falcatus, while there were no apparent population increases (all $b_{k}$ values $>-0.5$ ). The second PRC shows a slight decrease of Brachionus falcatus and Moina sp. at the beginning and at the end of the experimental period (data not shown). The different response of Moina sp. and Anuraeopsis sp. to salinity in the different temperature treatments is also indicated by the significance of the three-way ANOVA interaction at the beginning and at the end of the experimental period, respectively (Table S3), confirming that Moina sp. had a larger population abundance decrease at $20^{\circ} \mathrm{C}$ and Anuraeopsis sp. at $30^{\circ} \mathrm{C}$ (Fig. 3 ).

The PERMANOVA analysis showed that CPF affected the zooplankton community significantly from day 7 until the end of the experiment (Table 2), producing a (marginally) significant decrease of diversity and Cladocera abundance on day 7 and 14 (Table 3, Fig. 1). The interaction between temperature and CPF was significant after the application (day 7) and at the end of the experiment (day 28; Table 2). The PRC analysis showed that CPF explained $15 \%$ of variability at $20^{\circ} \mathrm{C}$, and $21 \%$ at $30^{\circ} \mathrm{C}$ (Table 4 ). At $20^{\circ} \mathrm{C}$, the maximum $\mathrm{CPF}$ effects were reached at end of the experimental period, while at $30^{\circ} \mathrm{C}$ the maximum effects were already reached on day 7 and shows smaller differences towards the end of the experiment, indicating partial community recovery. At $20^{\circ} \mathrm{C}$, the $\mathrm{CPF}$ application resulted in a decline of Lecane lunaris and Diaphanosoma sp., and a slight increase of Copepoda nauplii and Anuraeopsis sp. However, at $30^{\circ} \mathrm{C}$, there was a decline of Diaphanosoma sp. and Anuraeopsis sp., and no clear treatmentrelated increases (Fig. 4). The different responses to the CPF treatment of Diaphanosoma sp., Anuraeopsis sp. and Lecane lunaris are also displayed in Fig. 2, and the significant interactions are provided in Table S3.

The PERMANOVA analysis showed that the interaction between salinity and CPF was generally not significant, except for the last sampling date, and the interaction between the three stressors was not significant at any sampling date (Table 2). However, the interaction between salinity and CPF was significant for Cladocera (Table 3) on day 7 after the CPF application (Table 3). The abundance of that taxonomic group, which was clearly dominated by Diaphanosoma sp., was somewhere in between the effects caused 

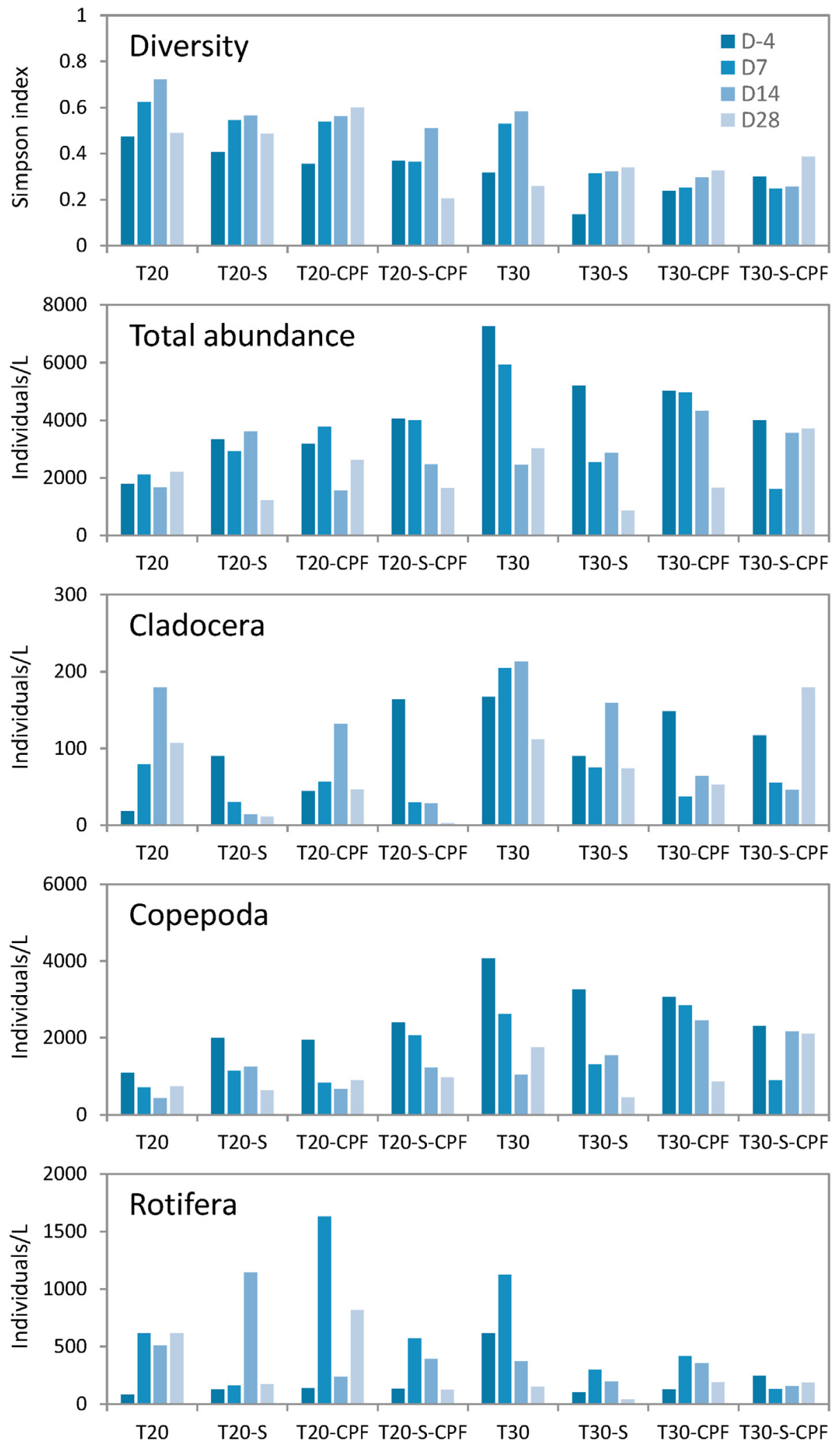

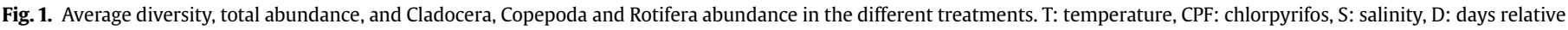
to the chlorpyrifos application. 
Table 4

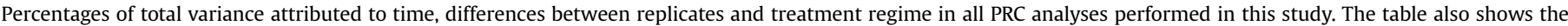

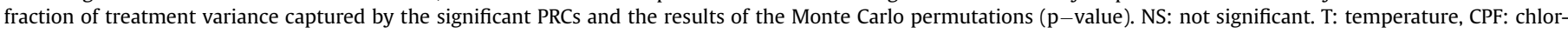
pyrifos, S: salinity.

\begin{tabular}{|c|c|c|c|c|c|c|}
\hline \multirow[t]{2}{*}{ Dataset } & \multicolumn{3}{|c|}{$\%$ of variance accounted for } & \multicolumn{3}{|c|}{$\begin{array}{l}\% \text { of variance explained by treatment regime captured by the } \\
\text { different PRCs ( } \mathrm{p} \text {-value) }\end{array}$} \\
\hline & Time & Differences between replicates & Treatment & First PRC & Second PRC & Third PRC \\
\hline $\mathrm{T}$ & 46.0 & 52.4 & 1.6 & $60.6(\mathrm{p}=0.02)^{\mathrm{a}}$ & NS & NS \\
\hline $\mathrm{S}$ at $\mathrm{T} 20$ & 21.2 & 57.4 & 21.4 & $64.8(\mathrm{p}=0.02)^{\mathrm{b}}$ & NS & NS \\
\hline $\mathrm{S}$ at $\mathrm{T} 30$ & 19.7 & 46.5 & 33.8 & $63.5(\mathrm{p}=0.02)^{\mathrm{b}}$ & $17.9(\mathrm{p}=0.04)^{\mathrm{d}}$ & NS \\
\hline CPF at T20 & 33.5 & 51.6 & 14.9 & $59.8(\mathrm{p}=0.05)^{\mathrm{b}}$ & NS & NS \\
\hline $\mathrm{CPF}$ at $\mathrm{T} 30$ & 29.6 & 48.9 & 21.5 & $66.9(\mathrm{p}=0.02)^{\mathrm{b}}$ & NS & NS \\
\hline $\mathrm{CPF}$ and $\mathrm{S}$ at $\mathrm{T} 20$ & 43.5 & 49.9 & 6.7 & $36.5(\mathrm{p}<0.01)^{\mathrm{c}}$ & $23.9(\mathrm{p}=0.03)^{\mathrm{c}}$ & NS \\
\hline $\mathrm{CPF}$ and $\mathrm{S}$ at $\mathrm{T} 30$ & 45.7 & 45.3 & 9.0 & $45.7(\mathrm{p}<0.01)^{\mathrm{c}}$ & $39.3(\mathrm{p}<0.01)^{\mathrm{c}}$ & $12.9(\mathrm{p}=0.02)^{\mathrm{d}}$ \\
\hline
\end{tabular}
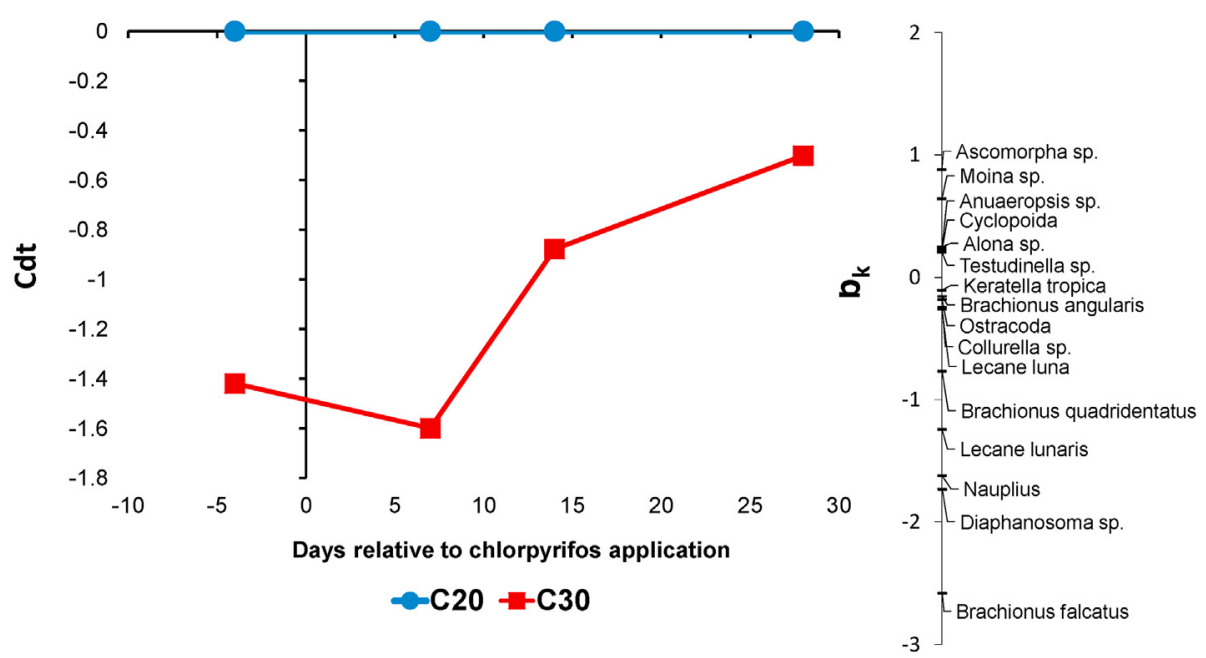

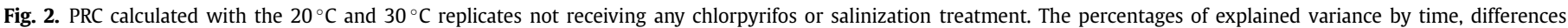
between replicates and treatment regime are shown in Table 4. The raw data on taxa counts is provided in Appendix I.

by salinity and CPF alone (Fig. 1), so that it can be classified as antagonistic. Diaphanosoma sp. also showed significant interactive effects on that sampling date (Table S3), however the abundances were so low (Fig. 3) that it was impossible to evaluate the response type.

The PRC analysis including the salinity and the CPF treatments at $20^{\circ} \mathrm{C}$ and $30^{\circ} \mathrm{C}$ showed that more than one PRC was significant (Table 4). As expected, by inspecting the first and second PRC it can be concluded that the majority of species responded similarly to the combination of both stressors at $20^{\circ} \mathrm{C}$ and $30^{\circ} \mathrm{C}$, except for Moina sp. (Figure S3), which showed a clear decline at $20^{\circ} \mathrm{C}$ and a notable increase at $30^{\circ} \mathrm{C}$ when both stressors (i.e., salinity and CPF) were present (Fig. 3). This is also supported by the marginally significant p-value calculated by the three-way ANOVA for the salinity and CPF interaction, although the triple interaction was not significant (Table S3). Overall, the variation partitioning analysis indicated that the influence of salinity was larger than the influence of CPF on the zooplankton community at $20^{\circ} \mathrm{C}$, while the contribution of each stressors was similar at $30^{\circ} \mathrm{C}$ (Table S2). Moreover, the first PRC of the combination of both stressors suggests that the community effects of salinity and $\mathrm{CPF}$ are more strongly correlated at $30^{\circ} \mathrm{C}$ than at $20^{\circ} \mathrm{C}$ (Figure S3).

\section{Discussion}

\subsection{CPF dissipation and water quality variables}

In this study, temperature notably enhanced CPF dissipation, while salinity contributed to a slightly reduced dissipation rate. Microbial activity associated to temperature variation has been discussed to be one the main factors that affects the dissipation of CPF from the water column (Racke, 1993), although other factors such as turbidity, organic matter (including algae) and sediment characteristics can also play an important role (Daam and Van den Brink, 2009). In an outdoor mesocosm performed under Mediterranean conditions, López-Mancisidor et al. (2008) calculated an average DT50 of 2.2 days (average water temperature was $20^{\circ} \mathrm{C}$ ), which is similar to the results of our study. The slight differences related to salinity may be explained by decreased hydrolysis rates (Wang and Hoffman 1991), and by the lower algae density in the water column observed in the salinity treatment (Table 1).

The assessment of the water quality variables indicated a decrease of chlorophyll- $a$ at $30^{\circ} \mathrm{C}$ and dissolved oxygen. The increase of temperatures resulted in an increase of zooplankton density, which could have contributed to an increasing grazing pressure on the phytoplankton community. Furthermore, salinity seemed to contribute to a reduction of phytoplankton. In our study, 

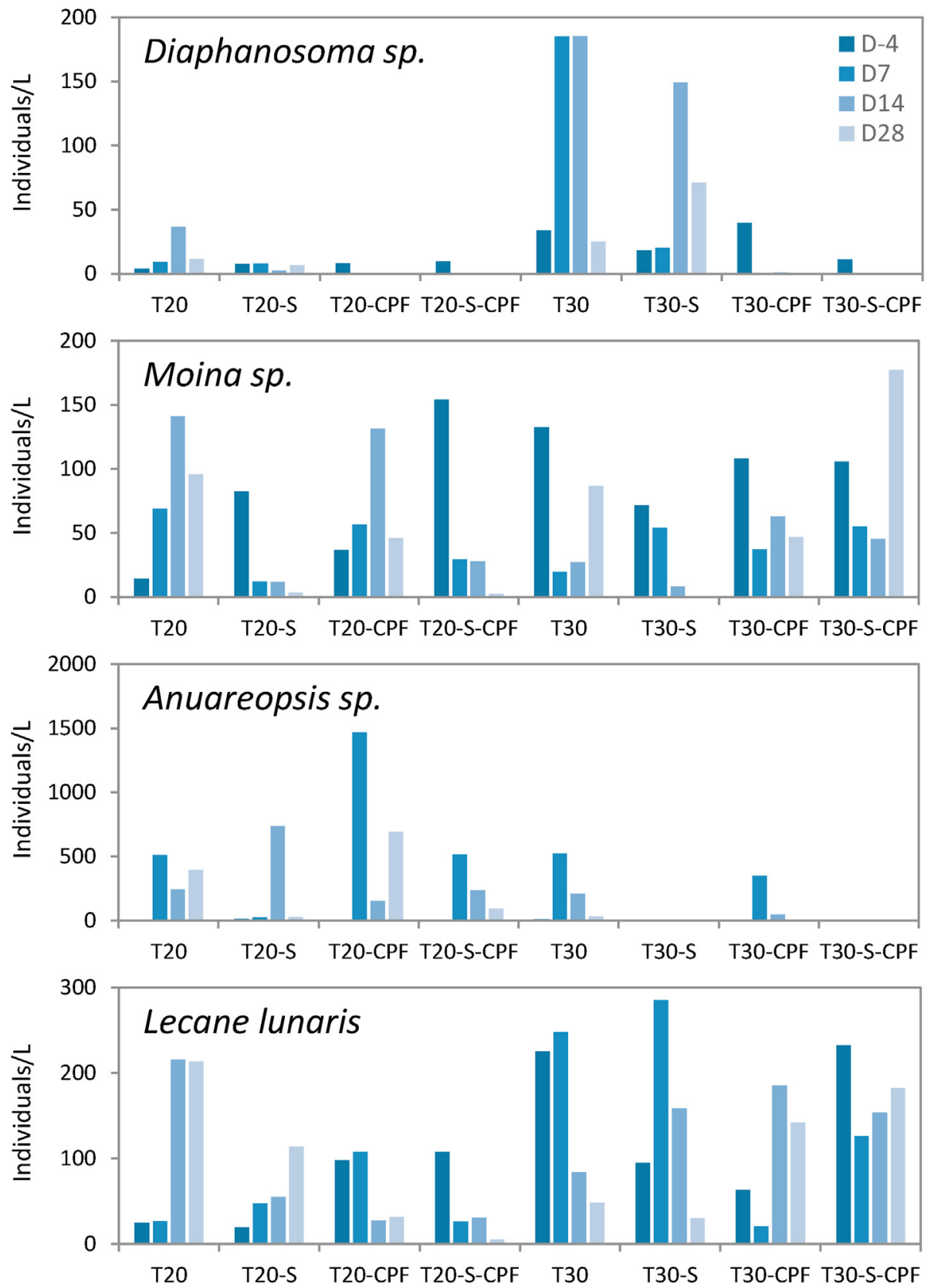

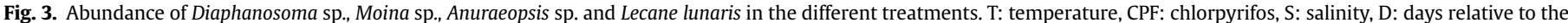
chlorpyrifos application.

the levels of ammonia were increased by temperature and salinity, probably due to accelerated organic matter decomposition of decaying planktonic organisms. In fact, we observed a flocculation and sedimentation of algae in these microcosms, which has been described as a response to biotic and abiotic stress (Sukenik and Shelef, 1984; Brady et al., 2014). The levels of unionized ammonia reached in the $30^{\circ} \mathrm{C}$ microcosms, and particularly in those also treated with salt and CPF, are expected to result in toxic effects on sensitive aquatic organisms (Arthur et al., 1987) and may thus have contributed to the changes observed in the zooplankton community. It should also be noted that the water sampled for nutrient analysis was relatively high as compared to the total water volume of the microcosms (8\%), so that there could be a slight impact created by this on later sampling days (e.g. day 28 ) which may have affected the natural dynamics of the planktonic communities in all microcosms.

\subsection{Zooplankton responses to varying temperatures}

Our experiment indicated that temperature was the most important factor influencing the zooplankton community, followed by salinity and CPF. Changes in water temperature, related to seasonality or climate change, have been reported as an important factor modifying the composition, structure and dynamics of zooplankton communities in wetland ecosystems, and hence, on ecosystem processes and services (Thompson et al., 2012; Gabler et al., 2017). In the present study, we show that at $30^{\circ} \mathrm{C}$ there was an abundance increase of all zooplankton groups (Cladocera, Copepoda and Rotifera). For many zooplankton taxa, temperature is considered an important factor that affects their metabolic rate and 
$\mathrm{S}$ at $\mathrm{T} 20$

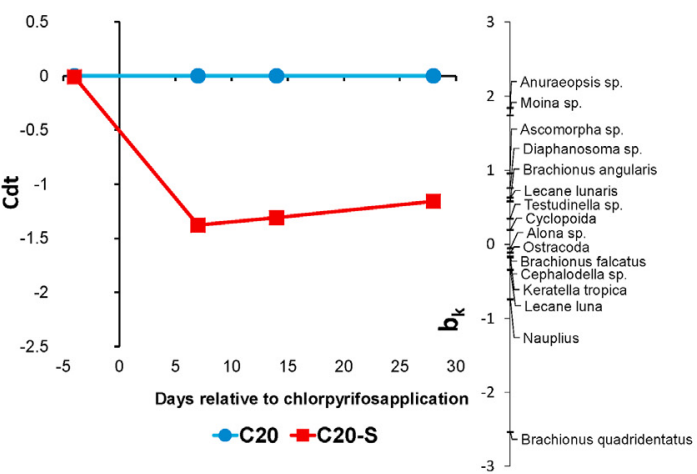

CPF at T20

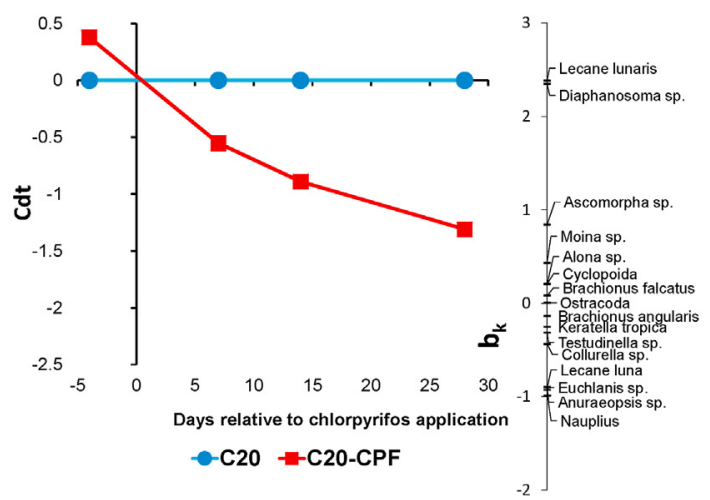

S at T30

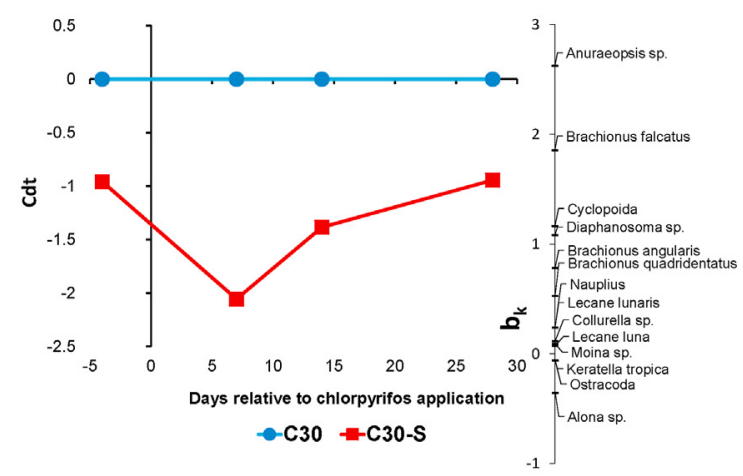

CPF at T30

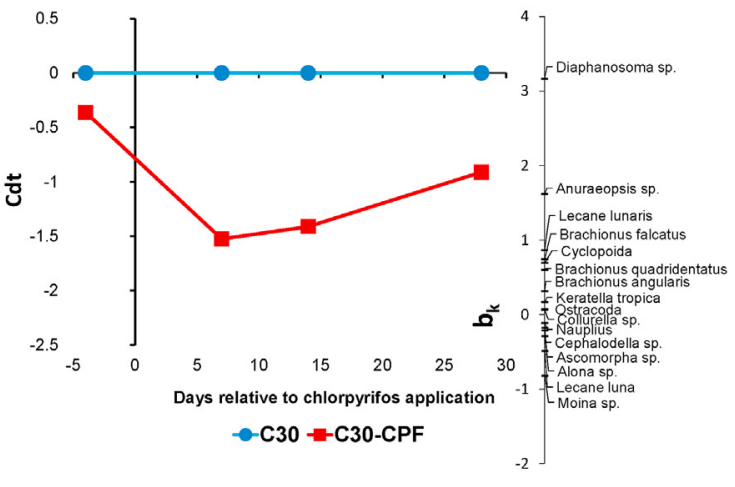

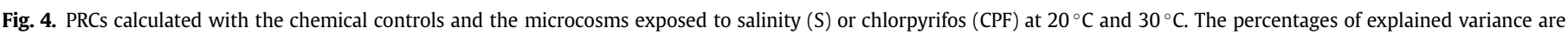
shown in Table 4. The raw data on taxa counts is provided in Appendix I.

the amount of energy allocated for egg production, hence, changing their life-history traits and population growth (Gillooly et al., 2001; Devreker et al., 2009). The taxa Brachionus falcatus, Diaphanosoma sp. and copepoda nauplii had an increased abundance at the beginning of the experiment at $30^{\circ} \mathrm{C}$, indicating a preference for high water temperatures. On the other hand, Ascomorpha sp. and Moina sp. abundance slightly decreased as response to the temperature increase. We also observed that community structure differences between the $20^{\circ} \mathrm{C}$ and $30^{\circ} \mathrm{C}$ controls were larger at the beginning of the experiment than at the end (Fig. 2), indicating a potential adaptation of some taxa to the new thermal scenario. According to the existing literature (Beaugrand et al., 2002; Arenas-Sánchez et al., 2019), higher temperatures favor the dominance of smaller organisms, but may also result in a favorable condition for competition and predation among smaller zooplankton groups.

\subsection{Zooplankton responses to salinity at different temperatures}

At $20^{\circ} \mathrm{C}$, salinity increase induced a decrease in zooplankton diversity and total abundance. Salinity also resulted in a significant decrease of Cladocera individuals and produced an increase of Copepoda (at Nauplius stages). This is in good agreement with the mesocosm study peformed by Thompson and Shurin (2012), who observed a significant increase of cyclopoid copepods after a slight salinity increase $(0.3 \mathrm{ppt})$. Some authors have argued that such structural changes in the zooplankton community are characteristic of brackish lagoons during high osmotic pressure periods, and are a consequence of reduced fitness of Cladocera and competitive exclusion by well adapted copepods (Brucet et al., 2009; Jensen et al., 2010). Other studies have demonstrated that short rises of salinity can result in the dominance of few Rotifera taxa
(Schallenberg et al., 2003; Anton-Pardo and Armengol, 2012; Coldsnow et al., 2017). Our experiment shows that at $20^{\circ} \mathrm{C}$, salinity resulted in a notable increase of Brachionus quadridentatus and a decrease of Anuraeopsis sp. (Fig. 4). This can be explained by the low tolerance of Anuraeopsis taxa to osmotic pressure as compared to Brachionus, as demonstrated by the growth curves calculated by Sarma et al. (2006) for these two genera under laboratory conditions. In addition, Anton-Pardo and Armengol (2012) found a high prevalence of Brachionus species in brackish coastal Mediterranean ponds, while Anuraeopsis fissa was one of the few Rotifera taxa that were distributed among ponds irrespective of salinity levels.

Our experiment shows a significant interaction between temperature and salinity on the zooplankton community. In fact, under warmer conditions $\left(30^{\circ} \mathrm{C}\right)$, salinity had a higher impact on the zooplankton community, reducing the abundance of all the taxonomic groups. It should be noted, however, that zooplankton abundances were in the majority of the cases still above the ones in the salinity treatments at $20^{\circ} \mathrm{C}$ because, as described above, temperature resulted in high zooplankton densities. For some particular taxa (e.g., Moina sp., Anuraeopsis sp.) salinity-related declines showed considerable differences between the two tested temperature conditions, which may be related to different metabolic rates and tolerances to osmotic pressure (Miracle and Serra, 1989), as well as the availability of phytoplankton resources and the presumable toxicity caused by unionized ammonia. Therefore, this study confirms that temperature influences the direct and indirect effects of salinity to the zooplankton community, so that seasonal temperature variation and climate change may significantly interact with the ecological effects caused by salinity. In addition, some studies have reported that the shift in the structure of zooplankton communities caused by salinity intrusion in coastal lagoons, leading towards a lower zooplankton abundance or the 
dominance of smaller and less efficient zooplanktonic grazers, may result in a functional diversity loss and increasing eutrophication risks (Jeppesen et al., 2015; Gutierrez et al., 2018).

\subsection{Zooplankton responses to CPF at different temperatures}

In the present study, CPF reduced zooplankton diversity, mainly affecting Cladocera. Similar results were observed in other model ecosystem experiments performed under Mediterranean-like conditions (Van Wijngaarden et al., 2005; López-Mancisidor et al., 2008; Pereira et al., 2017). At $30^{\circ} \mathrm{C}$, we found larger community effects in the first week after the insecticide application, but also partial recovery as compared to the $20^{\circ} \mathrm{C}$ treatment. This is in line with previous studies, which demonstrated a large influence of temperature in the response of aquatic organisms to pesticide stress (Patra et al., 2015; Rocha et al., 2016; Pawar et al., 2020), which affects community structure dynamics. For example, ArenasSánchez et al. (2019) found that the time to onset of effects caused by the insecticide lufenuron and the post-exposure recovery of zooplankton populations and communities was considerably faster at $28^{\circ} \mathrm{C}$ as compared to $20^{\circ} \mathrm{C}$.

Our study also shows that the indirect effects caused by CPF were influenced by temperature. At $20^{\circ} \mathrm{C}$, the reduction of Cladocera (mainly Diaphanosoma sp.) resulted in an increase of some Rotifera and Copepoda taxa. This caused a temporary increase of total abundance after the insecticide application at $20^{\circ} \mathrm{C}$ and indirect negative effects on chlorophyll- $a$. At $30^{\circ} \mathrm{C}$, such indirect increases in abundance were not observed, potentially due to the algae flocculation described above. In our study, the observed indirect effects were relatively mild, however they should not be neglected as these can result in long-term changes on the structure of aquatic communities and potentially affect predator-prey relationships at higher trophic levels (e.g., macroinvertebrates, fish; Thompson et al., 2015).

\subsection{Zooplankton responses to salinity and CPF under different temperatures}

Contrary to previous studies indicating synergistic effects of salinity and CPF on freshwater invertebrates (Song and Brown, 1998), our study shows that the interaction between these two stressors was generally not significant during the period of maximum toxicant effects (first week). Neither it was the triple interaction including temperature. The joint effects of salinity and $\mathrm{CPF}$ on the most sensitive taxonomic group (Cladocera) were found to be antagonistic, possibly due to the complex bound formation of CPF with salts and the resulting slightly reduced bioavailability (Maryoung et al., 2014). In line with this, Pawar et al. (2020) observed a reduction in the toxicity of CPF to the euryhaline white leg shrimp under higher salinity, and other studies report similar findings testing these stressor combinations on fish survival (Lavado et al., 2009; Maryoung et al., 2014) or assessing biochemical responses (Durieux et al., 2011).

Overall, our study shows that, at the tested stressor levels, salinity is a more severe stressor at $20^{\circ} \mathrm{C}$ than CPF; while at $30^{\circ} \mathrm{C}$, both had similar impacts and more correlated responses. This has implications for ecosystem management and suggests that under future climate change scenarios the influence of salinity on zooplankton communities can be confounded with that caused by temperature increase. Moreover, this study shows that the interaction between increasing temperatures, salinity and insecticide stress could contribute to a biodiversity decline in an additive manner. Further research should be dedicated to assess the interaction between other stressor combinations related to global change on Mediterranean wetlands and to explore their consequences for ecosystem service provision and management.

\section{Authors contribution}

Jéssica Andrade Vilas-Boas: Conceptualization, Methodology, Investigation, Validation, Formal analysis, Data curation, Writing original draft. Alba Arenas-Sánchez: Conceptualization, Methodology, Investigation, Validation, Formal analysis, Data curation, Writing - original draft. Marco Vighi: Conceptualization, Resources, Writing - review \& editing, Supervision. Susana Romo: Conceptualization, Writing - review \& editing. Paul Van den Brink: Formal analysis, Data curation, Writing - review \& editing. Roberto Júnio Pedroso Dias: Supervision, Conceptualization, Writing - review \& editing. Andreu Rico: Conceptualization, Methodology, Investigation, Validation, Formal analysis, Data curation, Supervision, Project administration, Writing - original draft.

\section{Declaration of competing interest}

The authors declare that they have no known competing financial interests or personal relationships that could have appeared to influence the work reported in this paper.

\section{Acknowledgments}

This study is part of the CICLIC project (Smart tools and technologies to assess the environmental fate and risks of Contaminants under Climate Change), funded by the Spanish Ministry of Science, Innovation and Universities (RTI 2018-097158-A-C32). The PhD of Jéssica Andrade Vilas-Boas was sponsored by the Coordenação de Aperfeiçoamento de Pessoal de Nível Superior-Brasil (CAPES) - Finance Code 001, (fellowship to JAVB) and the Conselho Nacional de Desenvolvimento Científico e Tecnológico (CNPq, Bolsa de Produtividade 2018) of Brazil (fellowship to RJPD). Andreu Rico is supported by a postdoctoral grant provided by the Spanish Ministry of Science, Innovation and University (IJCI-2017-33465). We thank the Valencian Agricultural Ministry for providing salinity and temperature data in the Albufera lagoon, and the Albufera's Natural Park Office for allowing zooplankton collection and for providing the corresponding permits.

\section{Appendix A. Supplementary data}

Supplementary data to this article can be found online at https://doi.org/10.1016/j.chemosphere.2020.129381.

\section{References}

American Public Health Association, 2005. Standard Methods for the Examination of Water and Wastewater. American Water Works Association/American Public Works Association/Water Environment Federation. https://doi.org/10.2105/ AJPH.51.6.940-a.

Anderson, M.J., 2001. A new method for non-parametric multivariate analysis of variance. Austral Ecol. 26, 32-46. https://doi.org/10.1111/ j.1442-9993.2001.01070.pp.x.

Anton-Pardo, M., Armengol, X., 2012. Effects of salinity and water temporality on zooplankton community in coastal Mediterranean ponds. Estuar. Coast Shelf Sci. 114, 93-99. https://doi.org/10.1016/j.ecss.2011.08.018.

Arenas-Sánchez, A., López-Heras, I., Nozal, L., Vighi, M., Rico, A., 2019. Effects of increased temperature, drought, and an insecticide on freshwater zooplankton communities. Environ. Toxicol. Chem. 38, 396-411. https://doi.org/10.1002/ etc.4304.

Arthur, J.W., West, C.W., Allen, K.N., Hedtke, S.F., 1987. Seasonal toxicity of ammoniato five fish and nine invertebrate species. Bull. Environ. Contam. Toxicol. 38 324-331.

Barbier, E.B., 2011. Wetlands as natural assets. Hydrol. Sci. J. 56, 1360-1373. https:// doi.org/10.1080/02626667.2011.629787.

Bassi, N., Dinesh Kumar, M., Sharma, A., Pardha-Saradhi, P., 2014. Status of wetlands in India: a review of extent, ecosystem benefits, threats and management strategies. J. Hydrol. Reg. Stud. 2, 1-19. https://doi.org/10.1016/ 
J.EJRH.2014.07.001

Beaugrand, G., Reid, P.C., Ibañez, F., Lindley, A., Edwards, M., 2002. Reorganization of north atlantic marine copepod biodiversity and climate. Science 296, 1692-1694. https://doi.org/10.1126/science.1071329.

Bracewell, S., Verdonschot, R.C.M., Rafl, C.M., Schäfer, R.B., Bush, A., Lapen, D.R., Van den Brink, P.J., 2019. Qualifying the effects of single and multiple stressors on the food web structure of Dutch drainage ditches using a literature review and conceptual models. Sci. Total Environ. 684, 727-740. https://doi.org/10.1016/ j.scitotenv.2019.03.497.

Brady, P.V., Phillip, I., Hewson, J.C., 2014. A coordination chemistry model of algal autoflocculation. Algal Res 5, 226-230. https://doi.org/10.1016/ j.algal.2014.02.004

Brucet, S., Boix, D., Gascón, S., Sala, J., Quintana, X.D., Badosa, A., 2009. Species richness of crustacean zooplankton and trophic structure of brackish lagoons in contrasting climate zones: north temperate Denmark and Mediterranean Catalonia (Spain). Ecography 32, 692-702. https://doi.org/10.1111/ j.1600-0587.2009.05823.x.

Cairns Jr., J., Heath, A.G., Parker, B.C., 1975. The effects of temperature upon the toxicity of chemicals to aquatic organisms. Hydrobiologia 47, 135-171.

Cañedo-Argüelles, M., Hawkins, C.P., Kefford, B.J., Schafer, R.B., Dyack, B.J., Crucet, S., Buchwalter, D., Dunlop, J., Fror, O., Lazorchak, J., Coring, E., Fernadez, H.R., Goodfellow, W., González Achem, A.L., Hatfield-Dodds, S., Karimov, B.K., Mensah, P., Olson, J.R., Piscart, C., Prat, N., Ponsá, S., 2016. Saving freshwater from salts. Science 351, 914-916. https://doi.org/10.1126/science.aad3488.

Cañedo-Argüelles, M., Schafer, R.B., Kefford, B., 2019. Salt in freshwaters: causes, effects and prospects - Introduction to the theme issue. Philos T. R. Soc. 374, 1-6. https://doi.org/10.1098/rstb.2018.0002.

Ccanccapa-Cartagena, A., Picó, Y., Ortiz, X., Reiner, E.J., 2019. Suspect, non-target and target screening of emerging pollutants using data independent acquisition: assessment of a Mediterranean River basin. Sci. Total Environ. 687, 355-368. https://doi.org/10.1016/j.scitotenv.2019.06.057.

Clarke, K.R., Gorley, R.N., 2015. Getting Started with PRIMER V7. Primer-E. Plymouth Marine Laboratory, Plymouth, p. 20.

Coldsnow, K.D., Mattes, B.M., Hintz, W.D., Relvea, R.A., 2017. Rapid evolution of tolerance to road salt in zooplankton. Environ. Pollut. 222, 1-7. https://doi.org/ 10.1016/j.envpol.2016.12.024.

Cortina-Puig, M., Istamboulie, G., Marty, J.L., Noguer, T., 2010. Analysis of Pesticide Mixtures Using Intelligent Biosensors. INTECH Open Access Publisher. https:// doi.org/10.5772/7157.

Daam, M.A., Van den Brink, P.J., 2009. Implications of differences between temperate and tropical freshwater ecosystems for the ecological risk assessment of pesticies. Ecotoxicology 19, 21-37. https://doi.org/10.1007/10.1007/ s10646-009-0402-6.

Devreker, D., Souissi, S., Winkler, G., Forget-Leray, J., Loboulenger, F., 2009. Effects of salinity, temperature and individual variability on the reproduction of Eurytemora affinis (Copepoda; Calanoida) from the Seine estuary: a laboratory study. J. Exp. Mar. Biol. Ecol. 368, 113-123. https://doi.org/10.1016/ j.jembe.2008.10.015.

Durieux, E.D.H., Farver, T.B., Fitzgerald, P.S., Eder, K.J., Ostrach, D.J., 2011. Natural factors to consider when using acetylcholinesterase activity as neurotoxicity biomarker in Young-Of-Year striped bass (Morone saxatilis). Fish Physiol. Biochem. 37, 21-29. https://doi.org/10.1007/s10695-010-9412-9.

EC, European Commission, 2020. Commission Implementing Regulation (EU) 2020/ 18 of 10 January 2020 concerning the non-renewal of the approval of the active substance chlorpyrifos. In: Accordance with Regulation (EC) No 1107/2009 of the European Parliament and of the Council Concerning the Placing of Plant Protection Products on the Market, and Amending the Annex to Commission Implementing Regulation (EU) No 540/2011.

Gabler, A.C., Osland, M.J., Grace, J.B., Stagg, C.L., Day, R.H., Stephen, B.H., Enwright, N.M., From, A.S., McCoy, M.L., McLeod, J.L., 2017. Macroclimatic change expected to transform coastal wetland ecosystems this century. Nat. Clim. Change 7, 142-417. https://doi.org/10.1038/nclimate3203.

Gillooly, J.F., Brown, J.H., West, G.B., Savage, V.M., Charnov, E.L., 2001. Effects of size and temperature on metabolic rate. Science 293, 2248-2251. https://doi.org/ 10.1126/science.1061967.

Gutierrez, M.F., Tavsanoglu, U.N., Vidal, N., Yu, J., Mello, F.T., Çakiroglu, A., He, H., Liu, Z., Jeppesen, E., 2018. Salinity shapes zooplankton communities and functional diversity and has complex effects on size structure in lakes. Hydrobiologia 813, 237-255. https://doi.org/10.1007/s10750-018-3529-8.

Hall Jr., L.W., Anderson, R.D., 1995. The influence of salinity on the toxicity of various classes of chemicals to aquatic biota. Crit. Rev. Toxicol. 25, 281-346. https:// doi.org/10.3109/10408449509021613.

Heugens, E.H.W., Hendriks, A.J., Dekker, T., van Straalen, N.M., Admiraal, W., 2001. A review of the effects of multiple stressors on aquatic organisms and analysis of uncertainty factors for use in risk assessment. Crit. Revi.Toxicol. 31, 247-284. https://doi.org/10.1080/20014091111695.

Hintz, W.D., Jones, D.K., Relyea, R., 2018. Evolved tolerance to freshwater salinization in zooplankton: life-history trade-offs, cross-tolerance and reducing cascading effects. Philos. T. R. Soc. B. 374, 20180012. https://doi.org/10.1098/ rstb.2018.0012.

Huang, X., Cui, H., Duan, W., 2020. Ecotoxicity of chlorpyrifos to aquatic organisms: a review. Ecotoxicol. Environ. Saf. 200, 110731. https://doi.org/10.1016/ j.ecoenv.2020.110731.

IPCC, Intergovernmental Panel on Climate Change, 2014. Climate change 2014: Synthesis report. Contribution of Working Groups I, II and III to the Fifth
Assessment Report of the Intergovernmental Panel on Climate Change. Geneva, Switzerland. Available at. https://www.ipcc.ch/report/ar5/syr/.

Jackson, M.C., 2018. Multiple stressors in freshwater ecosystems: biocides and climate change. Freshw. Biol. 27, 2-10. https://doi.org/10.1111/ j.1365-2427.2009.02395.x.

Jeppesen, E., Brucet, S., Naselli-Flores, L., Papastergiadou, E., Stefanidis, K., Noges, T. Noges, P., Attayde, J.L., Zohary, T., Coppens, J., Bucak, T., Fernandes Menezes, R., Sousa Freitas, F.R., Kernan, M., Sondergaard, M., Beklioglu, M., 2015. Ecological impacts of global warming and water abstraction on lakes and reservoirs due to changes in water level and related changes in salinity. Hydrobiologia 750 201-227. https://doi.org/10.1007/s10750-014-2169-x.

Jensen, E., Brucet, S., Meerhoff, M., Nathansen, L., Jeppesen, E., 2010. Community structure and diel migration of zooplankton in shallow brackish lakes: role of salinity and predators. Hydrobiologia 646, 215-229.

Klausmeyer, K.R., Shaw, M.R., 2009. Climate change, habitat loss, protected areas and the climate adaptation potential of species in Mediterranean ecosystems worldwide. PloS One 4, e6392. https://doi.org/10.1371/journal.pone.0006392.

Lavado, R., Rimoldi, J.M., Schlenk, D., 2009. Mechanisms of fenthion activation in rainbow trout (Oncorhynchus mykiss) acclimated to hypersaline environments. Toxicol. Appl. Pharmacol. 235, 143-152. https://doi.org/10.1016 j.taap.2008.11.017.

Liu, J.G., Diamond, J., 2005. China's environment in a globalizing world. Nature 435 1179-1186. https://doi.org/10.1038/4351179a.

López-Mancisidor, P., Carbonell, G., Marina, A., Fernández, C., Tarazona, J.V., 2008 Zooplankton community responses to chlorpyrifos in mesocosms under Mediterranean conditions. Ecotoxicol. Environ. Saf. 71, 16-25. https://doi.org 10.1016/j.ecoenv.2007.06.006.

Mantyka-Pringl, C.S., Martin, T.G., Rhodes, J.R., 2012. Interactions between climate and habitat loss effects on biodiversity: a systematic review and meta-analysis. Global Change Biol. 18 https://doi.org/10.1111/j.1365-2486.2011.02593.x, $1239-1125$.

Mantyka-Pringl, C.S., Martin, T.G., Moffatt, D.B., Linke, S., Rhodes, J.R., 2014. Understanding and predicting the combined effects of climate change and land-use change on freshwater macroinvertebrates and fish. J. Appl. Ecol. 51, 572-581 https://doi.org/0.1111/1365-2664.12236.

Maryoung, L.A., Lavado, R., Schlenk, D., 2014. Impacts of hypersaline acclimation on the acute toxicity of the organophosphate chlorpyrifos to salmonids. Aquat Toxicol. 152, 284-290. https://doi.org/10.1016/j.aquatox.2014.04.017.

McLusky, D.S., Bryant, V., Campbell, R., 1986. The effects of temperature and salinity on the toxicity of heavy metals to marine and estuarine invertebrates. Oceanogr. Mar. Biol. 24, 481-520.

Millán, A., Velasco, J., Gutiérrez-Cánovas, C., Arribas, P., Picazo, F., Sánchez-Fernández, D., Abellán, P., 2011. Mediterranean saline streams in southeast Spain: what do we know? J. Arid Environ. 75, 1352-1359. https:// doi.org/10.1016/j.jaridenv.2010.12.010.

Miracle, M.R., Serra, M., 1989. Salinty and temperature influence in rotifer life history characteristics. In: Rotifer Symposium V. Springer, Dordrecht, pp. 81-102.

Moreno-González, R., León, V.M., 2017. Presence and distribution of current-use pesticides in surface marine sediments from a Mediterranean coastal lagoon (SE Spain). Environ. Sci. Pollut. Res. 24, 8033-8048. https://doi.org/10.1007 s11356-017-8456-0.

Navarro-Ortega, A., Acuña, V., Batalla, R.J., Blasco, J., Conde, C., Elorza, F.J., Elosegi, A., Francés, F., La-Roca, F., Muñoz, I., Petrovic, M., 2012. Assessing and forecasting the impacts of global change on Mediterranean rivers. Environ. Sci. Pollut. Res. 19, 918-933. https://doi.org/10.1007/s11356-011-0566-5.

Nielsen, D.L., Brock, M.A., Rees, G.N., Baldwin, D.S., 2003. Effects of increasing salinity on freshwater ecosystem in Australia. Aust. J. Bot. 51, 655-665. https:// doi.org/10.1071/BT02115.

OECD, Organisation for Economic Co-operation and Development, 2000. Guidance Document on Aquatic Toxicity Testing of Difficult Substances and Mixtures. Series on Testing and Assessment, vol. 23. ENV/JM/MONO, Paris, France (2000)

OECD, 2006. Organisation for Economic Co-operation and Development. Freshwater Alga and Cyanobacteria Growth Inhibition Test. Guideline 201. Paris France.

Osland, M.J., Enwright, N.M., Day, R.H., Gabler, C.A., Stagg, C.L., Grace, J.B., 2016 Beyond just sea-level rise: considering macroclimatic drivers within coastal wetland vulnerability assessments to climate change. Global Change Biol. 22, 1-11. https://doi.org/10.1111/gcb.13084.

Patra, R.W., Chapman, J., Lim, R.P., Gehrke, P.C., Sunderam, R.M., 2015. Interactions between water temperature and contaminant toxicity to freshwater fish. Environ. Toxicol. Chem. 34, 18091817. https://doi.org/10.1002/etc.2990.

Pawar, A.P., Sanaye, S.V., Shyama, S., Sreepada, R.A., Dake, A.S., 2020. Effects of salinity and temperature on the acute toxicity of the pesticides, dimethoate and chlorpyrifos in Post-larvae and juveniles of the whiteleg shrimp. Aquacult. Rep. 16, 100240. https://doi.org/10.1016/j.aqrep.2019.100240.

Pereira, A.S., Cerejeira, M.J., Daam, M.A., 2017. Toxicity of environmentally realistic concentrations of chlorpyrifos and terbuthylazine in indoor microcosms. Chemosphere 128, 348-355. https://doi.org/10.1016/j.chemosphere.2017.05.032.

Pérez-Ruzafa, A., Marcos, C., Pérez-Ruzafa, I., Pérez-Marcos, M., 2010. Coastal lagoons: "transitional ecosystems" between transitional and coastal waters. J. Coast Conserv. 15, 369-392. https://doi.org/10.1007/S11852-010-0095-2.

Pérez-Ruzafa, A., Marcos, C., Pérez-Ruzafa, I.M., 2011. Mediterranean coastal lagoons in an ecosystem and aquatic resources management context. Phys. Chem. Earth 36, 160-166. https://doi.org/10.1016/j.pce.2010.04.013. 
Peres-Neto, P.R., Legendre, P., Dray, S., Borcard, D., 2006. Variation partitioning of species data matrices: estimation and comparison of fractions. Ecology 87, 2614-2625. 2.0.CO;2.

Picó, Y., Alvarez-Ruiz, R., Alfarhan, A.H., El-Sheikh, M.A., Alshahrani, H.O., Barceló, D., 2019. Pharmaceuticals, pesticides, personal care products and microplastics contamination assessment of $\mathrm{Al}$-Hassa irrigation network (Saudi Arabia) and its shallow lakes. Sci. Total Environ. 701, 135021. https://doi.org/ 10.1016/j.scitotenv.2019.135021.

Racke, K.D., 1993. Environmental fate of chlorpyrifos. Rev. Environ. Contam. Toxicol. 131, 1-154.

Rico, A., Dafouz, R., Vighi, M., Rodríguez-Gil, J.L., Daam, M.A., 2020. Use of postregistration monitoring data to evaluate the ecotoxicological risks of pesticides to surface waters: a case study with chlorpyrifos in the Iberian Peninsula. Environ. Toxicol. Chem. https://doi.org/10.1002/etc.4927. In press.

Rocha, A.C.S., Reis-Henriques, M.A., Galhano, V., Ferreira, M., Guimaraes, L., 2016. Toxicity of seven priority hazardous and noxious substances (HNSs) to marine organisms: current status, knowledge gaps and recommendations for future research. Sci. Total Environ. 542, 728-749. https://doi.org/10.1016/ j.scitotenv.2015.10.049.

Rojo, C., Carramiñana, M., Cócera, D., Roberts, G.P., Puche, E., Calero, S., Rodrigo, M.A., 2017. Different responses of coexisting Chara species to foreseeable Mediterranean temperature and salinity increases. Aquat. Bot. 138, 53-63. https://doi.org/10.1016/j.aquabot.2017.01.003.

Rokneddine, A., Chentoufi, M., 2004. Study of salinity and temperature tolerance limits regarding four crustacean species in a temporary salt water swamp (Lake Zima, Morocco). Anim. Biol. Leiden 54, 237-253. https://doi.org/10.1016/ $10.1163 / 1570756042484719$.

Romo, S., Villena, M., Sahuwuillo, M., Soria, J.M., Giménez, M., Alfonso, T., Vicente, E., Miracle, M.R., 2005. Response of a shallow Mediterranean lake to nutriente diversion: does it follow similar patterns as in northern shallow lakes? Freshw. Biol. 50, 1706-1717. https://doi.org/10.1111/j.1365-2427.2005.01432.x.

Romo, S., Soria, J., Olmo, C., Flor, J., Calvo, S., Ortells, R., 2016. Nutrients and carbon in some Mediterranean dune ponds. Hydrobiologia 782 (2016), 97-109. https:// doi.org/10.1007/s10750-016-2692-z.

Simpson, E.H., 1949. Measurement of diversity. Nature 163 (4148), 688-688.

Sarma, S.S.S., Nandini, S., Morales-Ventura, J., Delgado-Martinez, I., Gonzalez-Velverde, L., 2006. Effects of $\mathrm{NaCl}$ salinity on the population dynamics of freshwater zooplankton (rotifers and cladocerans). Aquat. Ecol. 40
(349), 2006. https://doi.org/10.1007/s10452-006-9039-1.

Sahin, M.D., Aybek, E.C., 2019. Jamovi: an easy to use statistical software for the social scientists. International Journal of Assessment Tools in Education 6 670-692.

Schallenberg, M., Hall, C.J., Burns, C.W., 2003. Consequences of climate-induced salinity increases on zooplankton abundance and diversity in coastal lakes. Mar. Ecol. Prog. Ser. 251, 181-189. https://doi.org/10.3354/meps251181.

Song, M.Y., Brown, J.J., 1998. Osmotic effects as a factor modifying insecticide toxicity on Aedes and Artemia. Ecotoxicol. Environ. Saf. 41, 195-202. https:// doi.org/10.1006/eesa.1998.1693.

Sukenik, A., Shelef, G., 1984. Algal autof iocculation-verif ication and proposed mechanism. Biotechnol. Bioeng. 26, 142-147. https://doi.org/10.1002/ bit.260260206.

Ter Braak, C.J.F., Šmilauer, P., 2012. Canoco Reference Manual and User's Guide: Software for Ordination. Microcomputer Power, Ithaca, NY, USA, p. 496, Version 5.0

Thompson, P.L., Shurin, J., 2012. Regional zooplankton biodiversity provides limited buffering of pond ecosystems against climate change. J. Anim. Ecol. 81, 251-259. https://doi.org/10.1111/j.1365-2656.2011.01908.x.

Thompson, M.S.A., Bankier, C., Bell, T., Dumbrell, A.J., Gray, C., Ledger, M.E. Lehmann, K., McKew, B.A., Sayer, C.D., Shelley, F., Trimmer, M., Warren, S.L., Woodward, G., 2015. Gene-to-ecosystem impacts of a catastrophic pesticide spill: testing a multilevel bioassessment approach in a river ecostystem. Freshw. Biol. 61, 2037-2050. https://doi.org/10.1111/fwb.12676.

Valencian Agricultural Ministry, 2020. Coselleria d'Agricultura, Desenvolupament Rural, Emergència Climàtica I Transició Ecològica. Monitoring Program of Wetland Ecosystems. Available at: http://www.agroambient.gva.es/es/web/ espacios-naturales-protegidos/programa-de-seguimiento-de-zonas-humedas. Accessed on the 4th of September of 2019.

Van den Brink, P.J., Ter Braak, C.J.F., 1999. Principal response curves: analysis of time dependent multivariate responses of biological community to stress. Environ. Toxicol.and Chem. 18, 138-148. https://doi.org/10.1002/etc.5620180207.

Van Wijngaarden, R.P.A., Brock, T.C.M., Douglas, M.T., 2005. Effects of chlorpyrifos in freshwater model ecosystems: the influence of experimental conditions on ecotoxicological thresholds. Pest Manag. Sci. 61, 923-935. https://doi.org/ $10.1002 /$ ps.1084.

Wang, T.C., Hoffman, M., 1991. Degradation of organophosphorus pesticides in coastal water. J. AOAC Int. 74, 883-886. https://doi.org/10.1093/jaoac/74.5.883. 